Jurnal Teknologi, 41(D) Dis. 2004: 53-66

(C) Universiti Teknologi Malaysia

\title{
MICROSTRIP BANDWIDTH ENHANCEMENT USING USING LOG PERIODIC TECHNIQUE WITH INSET FEED
}

\author{
MOHAMAD KAMAL A RAHIM ${ }^{1}$ \& PETER GARDNER ${ }^{2}$
}

\begin{abstract}
This paper describes the various techniques to improve the bandwidth of a microstrip antenna. One of the techniques that has been discussed in detail is the log periodic technique. The design, simulation, and fabrication of log periodic antenna (LPA) with inset feed method has been discussed. The antenna has been designed with eleven element array. The performance of the antenna has been investigated in terms of bandwidth, gain relative to a dipole antenna, cross-polar isolation, and beamwidth.
\end{abstract}

Keywords: Microstrip antenna, log periodic antenna, wideband antenna, bandwidth, gain

\begin{abstract}
Abstrak. Ketas kerja ini menerangkan berbagai teknik untuk memperbaiki lebar jalur antena mikrojalur. Salah satu teknik yang dibincangkan secara khusus adalah teknik log periodik. Reka bentuk, penyelakuan dan fabrikasi antena log periodik dengan cara suapan inset telah dibincangkan. Antena telah direka bentuk dengan tatasusunan sebelas unsur. Prestasi antena tersebut dikaji dari segi lebar jalur, gandaan relatif kepada antenna dwikutub, pemencilan kutub silang dan lebar alur.
\end{abstract}

Kata kunci: Antena mikrojalur, antena log periodik, antena jalur lebar, lebar jalur, gandaan

\subsection{INTRODUCTION}

Antennas with physically wide bandwidth have been much sought after for several years. A wide bandwidth in some applications, the antenna does not limit the system bandwidth and hence facilitates the use of filters, amplifiers, mixers, oscillators, and other components. Other application with wider bandwidth is the fundamental requirement such as in pulse moving target and ground penetrating radar.

Microstrip antenna has gained popularity because of their small size and light weight. However, a limitation of microstrip antenna is the narrow bandwidth of the basic element. The bandwidth of a basic patch element is usually $1-3 \%$. The bandwidth of the antenna can be increased by reducing the substrate permittivity (er) or increasing its thickness (h). However, there are two problems associated with increasing the substrate thickness. One of the problems is the radiation and reactance associated

Wireless Communication Centre, Faculty of Electrical Engineering, Universiti Teknologi Malaysia, 81310 UTM Skudai Johor. E-mail: mkamal@fke.utm.my

2 Electronic, Elec. and Comp. Eng., The University of Birmingham, Edgbaston, Birmingham B15 2TT, U.K. E-mail: p.gardner@bham.ac.uk 
with the feed junction. The other problem is an increase in the surface wave effects [1]. In order to avoid these problems, a number of different methods has been introduced to improve the bandwidth of the microstrip antenna.

The bandwidth of the antenna is defined as the range of frequencies, over which the performance of the antenna with respect to some characteristic conforms to a specific standard [1]. The bandwidth of the antenna depends on the patch shape, resonant frequency, dielectric constant, and the thickness of the substrate. The bandwidth enhancement of a microstrip antenna has been directed towards improving the impedance bandwidth of the antenna element.

The impedance variation with the frequency of the antenna element results in a limitation of the frequency range, over which the element can be matched to its feed line. Impedance bandwidth is usually specified in terms of a return loss or maximum SWR typically less than 2.0 or 1.5 over a frequency range. Conversion of bandwidth from one SWR level to another can be accomplished by using the relation between bandwidth (BW) and quality factor (Q) [1]:

$$
\text { Bandwidth }=\frac{S-1}{Q \sqrt{S}}
$$

where $S$ = standing wave ratio

$Q=$ quality factor

SWR $(S)$ can be defined in terms of the input reflection coefficient as:

$$
S=\frac{1+|\Gamma|}{1-|\Gamma|}
$$

$\Gamma$ is the reflection coefficient at the feed point of the antenna. It can be defined in terms of input impedance $\left(Z_{i n}\right)$ of the antenna and the characteristic impedance $\left(Z_{o}\right)$ of the feedline. It is given by:

$$
\Gamma=\frac{Z_{\text {in }}-Z_{0}}{Z_{\text {in }}+Z_{0}}
$$

\subsection{TECHNIQUES TO IMPROVE BANDWIDTH}

Various techniques have been introduced to enhance the bandwidth of a microstrip antenna. Most of the work done for bandwidth enhancement has been directed towards improving the impedance bandwidth of the antenna element, since the narrow bandwidth of the basic element is usually the dominant characteristic that limits its application. Several methods have been introduced as a solution to the bandwidth problem as discussed below. 


\subsection{Multilayer Structure Antenna}

This method increases the overall height of the antenna but the size in the plane remains the same as the single patch antenna. There are two different types of multi-layer structure antenna. One is the electromagnetically coupled microstrip antenna (ECMSA) and the other is the aperture coupled miscrostrip antenna (ACMSA). The patches can be fabricated on different substrates and air gaps or foam material can be introduced between these layers to increase the bandwidth. Figure 1 (a) shows a multi-layer antenna constructed by stacking two elements feeding the top patch by a coaxial connector through the ground plane [2]. Two different operating frequencies resulted; the lower frequency was relatively steady over a range of different diameters for the upper conductor. The second resonant frequency was highly dependent on the radius of the two patches. The bandwidth achieved was up to $25 \%$ from the centre frequency and the standing wave ratio was less than 2 . Varying the value of the two heights and adjusting the value of $\varepsilon_{\mathrm{r} 2}$ can improve the bandwidth.

If one of the layers in the multi-layer structure antenna is replaced by an air gap, the bandwidth of the antenna can be further increased. This technique is called bandwidth enhancement using air gap [3]. This technique is similar to the multi-layer structure antenna, where the substrate can be replaced with air. This method uses two layers: one is a substrate of thickness (h), and the other is an air region of thickness (d). The effective permittivity is evidently reduced tending toward that of free space. Figure 1 (b) shows this technique. This configuration is capable of achieving a bandwidth of $10 \%$.

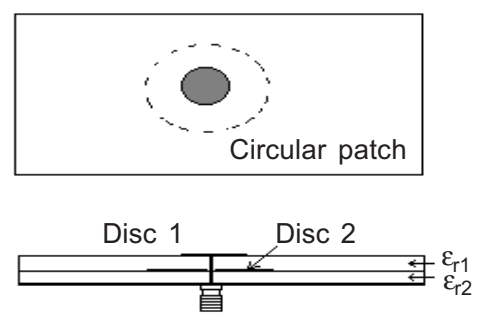

(a) dielectric stacked [2]

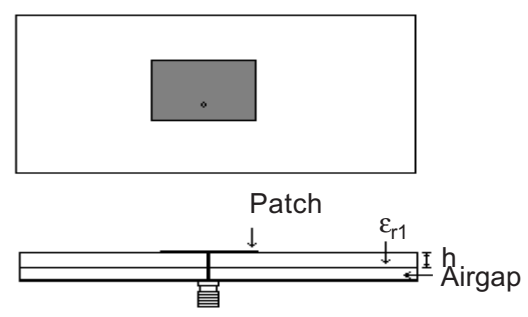

(b) airgap stacked [3]

Figure 1 Bandwidth enhancement using multi-layer technique

\subsection{Microstrip Antenna Using Parasitic Element}

In this method, an additional patch resonator is placed close to the microstrip antenna. Such a patch is known as a parasitic patch. The gap between the main radiating element and the additional resonator is chosen for optimum bandwidth. If the frequencies of these two patches are close to each other, then a broad bandwidth can be obtained. The overall VSWR will be the superposition of the responses of the two resonators resulting in a wide bandwidth. Figure 2(a) shows co-planar metallic strips coupled to 
the main patch [4]. A bandwidth up to 6-7 times that of a single rectangular patch was reported. The bandwidth can be increased by varying the length of the parasitic patches. A bandwidth of $10.5 \%$ was obtained by this method. Wu and Wong [5] suggested that the bandwidth of a microstrip antenna can also be enhanced with directly coupled and parasitic patches. This configuration is shown in Figure 2(b). It has a bandwidth of $12.7 \%$ with $10 \mathrm{~dB}$ return loss.

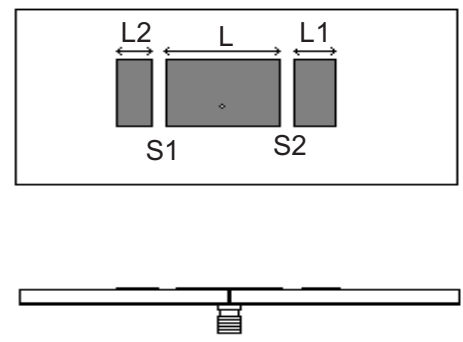

(a) parasitic at edge of radiating [4]

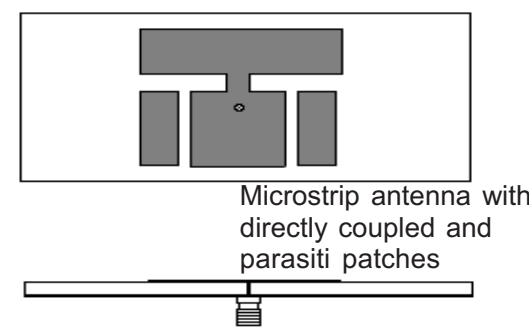

(b) directly coupled and parasitic [5]

Figure 2 Bandwidth enhancement using parasitic elements

\subsection{Log Periodic Technique}

Log Periodic Antenna (LPA) is a broadband antenna that has impedance and radiation characteristics that are regularly repetitive as a logarithmic function of the excitation frequency. The length and spacing of the elements of log periodic antennas increase logarithmic from one end to another [6]. The principle of log periodic antennas (LPA) requires all the dimensions of the array elements to be scaled in a log periodic manner, to achieve a corresponding scaling in frequencies. The quasi log periodic antenna was achieved by arranging different narrow bandwidth radiators, each having its own frequency band of operation [7]. The largest and smallest dimensions of the structures can be selected. Bandwidths up to multi-octave frequency have been achieved using this technique [7]. Figure 3 shows two different configurations of log periodic technique using microstrip antennas. The series fed log periodic array with a simple co-planar feed network [8], has a bandwidth of $22 \%$, with SWR $<2.6$, and with a reasonable gain in the broadside direction $>5.5 \mathrm{~dB}$. In the suspended microstrip configuration, the presence of the air gap increases the total height and reduces the effective dielectric constant. This result will increase the bandwidth of the antenna. The measured VSWR is better than 2.3, from 1.3 to $4.0 \mathrm{GHz}$. A nine element log periodic microstrip slot antenna array operating in the $\mathrm{X}$ band was designed using FDTD [9]. The results were verified with a measurement and the bandwidth obtained is $33 \%$. 

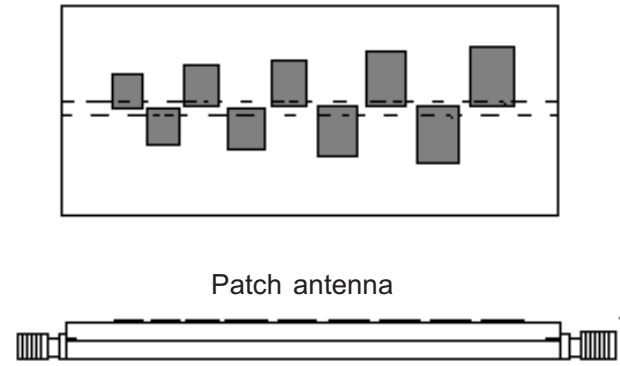

(a) electromagnetically coupled

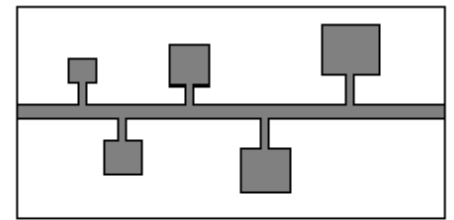

Patch antenna

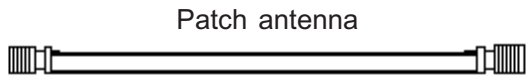

(b) series feed

Figure 3 Bandwidth enhancement using log periodic

\subsection{Patches with Special Shape or Technique}

Using specially shaped microstrip patches can increase the bandwidth of the microstrip antenna. The bow tie antenna as shown in Figure 4(a) has an inherently broad impedance bandwidth [10]. This antenna has been used in the frequency range of 94 to $466 \mathrm{GHz}$ for linear imaging arrays, plasma diagnostic, and radio astronomy. Another method that can be used to increase BW of the patch antenna is by using stepped or wedge shaped microstrip [11]. The bandwidth of this structure can be obtained up to $25 \%$. This configuration is shown in Figure 4(b). A novel E shaped antenna had been proposed by Ooi et. al [12]. An impedance bandwidth of about 33.8\% is achieved by the proposed $\mathrm{E}$ plane antenna. The radiation pattern is relatively constant through the band.

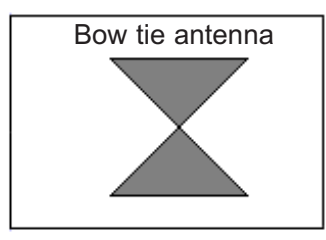

(a) bow tie shape[10]

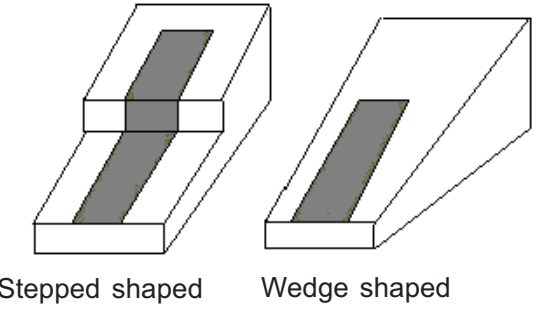

(b) stepped and wedge shape[11]

Figure 4 Bandwidth enhancement using special shape

\subsection{Patches with Non-contact Feeding Technique}

In this approach, the end of the feed probe is not directly in contact with the patch. This arrangement forms a series capacitance that can be controlled by adjusting the gap. The approach of Hall [13] was to feed the patch with a coaxial probe but with a circular or linear gap in the patch conductor, around the feed point. This gap must be 
narrow to obtain sufficient coupling to the patch, to achieve a bandwidth up to $30 \%$. Figure 5(a) shows this configuration. Aperture coupling is another non-contact method of feeding the patch antenna. In 1985, Pozar proposed the bandwidth enhancement using aperture coupling [14]. By optimising the various parameters such as aperture dimensions, length of the feed line, and aperture location or shape of coupling aperture, a bandwidth of nearly $70 \%$ has been achieved. Another related method is to use two layers proximity coupled, as shown in Figure 5(b) [15]. In this method, a microstrip feed line is placed on the lower substrate, and terminated in an open end at a point approximately below the mid point of the patch. When the tuning stub is not connected, the input impedance is approximately $40 \mathrm{ohm}$ at the resonance. The impedance matching is obtained by connecting a single stub. The bandwidth from this technique is $13 \%$ for VSWR $<2$.

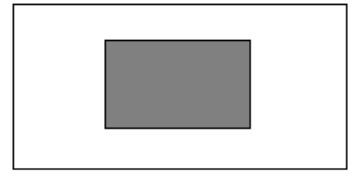

Patch antenna

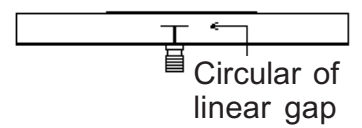

(a) probe with circular or linear [13]
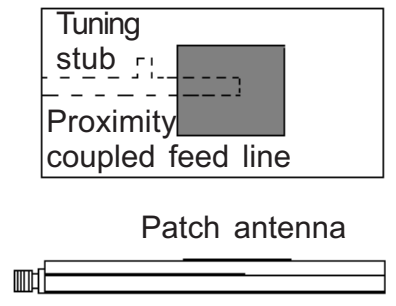

(b) proximity coupled [15]

Figure 5 Bandwidth enhancement using non-contact feeding

\subsection{Microstrip Antenna Using Impedance Matching}

The microstrip antenna is attached with a separate loss less matching network without altering the antenna element itself, as shown in Figure 6. The bandwidth performance of the matched antenna is generally best when the network is mounted as close as possible to the radiating element. The techniques by Pues \& Van de Capelle obtained a bandwidth of 10-12\%, using a co planar network [16].

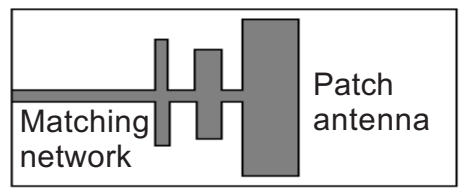

西配

Figure 6 Bandwidth enhancement using impedance matching [16] 


\subsection{Microstrip Antenna with Different Shaped Slot}

The bandwidth of a single element antenna can also be increased by making a pair of U shaped slots [17,18] or double bent slots [19]. The larger bandwidth is because of a reduction in the quality factor $(Q)$ of the patch resonator, which is due to less energy being stored beneath the patch and higher radiation. Figure 7(a) shows the configuration of a microstrip rectangular patch antenna with a pair of U-shaped slots. The bandwidth can be as large as about 2.6 times that of a corresponding conventional rectangular antenna. For a pair of double bent slots close to the patch's non radiating edges and an additional bent slot centred on the patch's centre line, the bandwidth is up to about 2.8 times that of the conventional rectangular patch antenna. This configuration is shown in Figure 7(b). Further increases in bandwidth can be obtained by stacking these modified patches with different layers of dielectric, air gap or foam material.

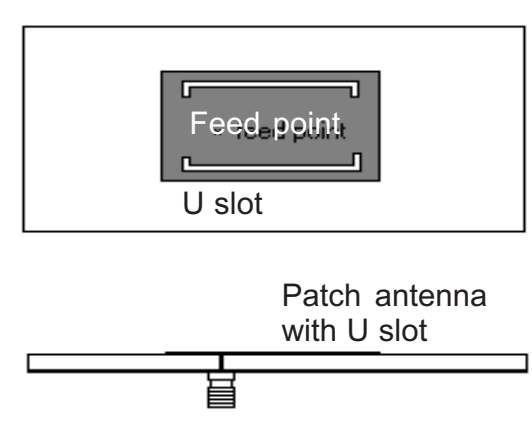

(a) U slot [17]

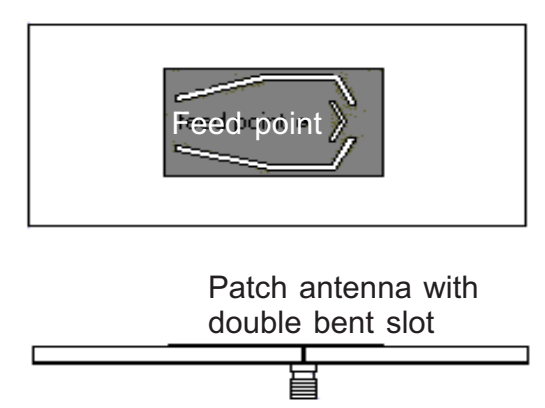

(b) Double bent slot [19]

Figure 7 Bandwidth enhancement using different slot shape

\subsection{DESIGN CONSIDERATION FOR LOG PERIODIC ANTENNA (LPA) WITH INSET FEED}

A frequency independent antenna (FIA) is defined as an antenna, which has no theoretical bandwidth limitations [6]. This statement implies that its geometry is selfscaleable through an infinite range such that the antenna reveals an almost constant performance. In general, the geometry of a frequency independent antenna is a multiplicity of adjoining cells. Each cell is scaled in dimensions relative to the adjacent cell, by a factor that remains constant within the structure. The cells may be two or three dimensional. If $L_{n}$ represents some dimension of the $n^{\text {th }}$ cell, and $L_{n+1}$ is the corresponding dimension of the $(n+1)^{\text {th }}$ cell, then the relationship between adjacent cells can be stated as:

$$
\frac{L_{n+1}}{L_{n}}=\tau
$$


The design principle for log periodic FIAs requires scaling of dimensions from period to period so that performance is periodic with the logarithm of frequency. This principle can be applied to an array of patch antennas. The patch length $(L)$, the width $(W)$, and the inset $(I)$ are related to the scale factor $\tau$ by:

$$
\tau=\frac{L_{m+1}}{L_{m}}=\frac{W_{m+1}}{W_{m}}=\frac{I_{m+1}}{I_{m}}
$$

If we multiply all dimensions of the array by $\tau$, it scales into itself with element $m$ becoming element $m+1$, element $m^{+1}$ becoming element $m+2$, etc. This self - scaling property implies that the array will have the same radiating properties at all frequencies that are related by a factor of $\tau$, that is,

$$
f_{1}, f_{2}=\tau f_{1}, f_{3}=\tau^{2} f_{1}, f_{4}=\tau^{3} f_{1}, \quad \text { etc. }
$$

We note that:

$$
\ln \frac{f_{2}}{f_{1}}=\ln \tau, \ln \frac{f_{3}}{f_{1}}=2 \ln \tau, \quad \text { etc. }
$$

Hence $\tau$ is called log periodic. The design process of log periodic antenna is described as below. The log periodic antenna is constructed from the microstrip transmission line and the imported $S_{11}$ data for a single element patch antenna simulated using momentum. The square patch microstrip antenna has been chosen as the basic single element for the array. A square patch $(W=L)$ has been used to avoid higher order modes that could disturb the radiation pattern and the polarisation. The single element antenna has been simulated using momentum.

The single element of the patch is scaled log periodically with scaling factor of 1.05. Each individual antenna has an individual $S_{11}$ parameter data file. The $S$ parameter data is exported to the schematic diagram as shown in Figure 8. The distance between element $(m)$ and element $(m+1)$ is determined according to the next higher frequency element of the antenna. The input looking into the next higher frequency must be open circuit before the next element $(m+1)$ is connected to the schematic diagram. In this model, the distance between two patches is not necessarily half wavelength and varying log periodically. The microstrip antenna feed line is a quarter wavelength long. This value is scaled log periodically.

The inset feed distance of the microstrip antenna is chosen for $50 \mathrm{ohm}$ input impedance and it is scaled log periodically. This model can be used for any element of log periodic patch antenna. The design of a quasi log periodic microstrip antenna can be carried out as follows:

(a) Choose the first resonance frequency and scale it log periodically for the subsequent resonance frequencies.

(b) Calculate the patch dimension $(W=L)$ for a square patch antenna and the inset 
feed dimensions for input impedance of $50 \mathrm{ohm}$ at resonance, and scale log periodically for the next patch.

(c) The distances between the branch lines are determined so that the input impedance looking into the next higher frequency is open circuit.

Figure 8 shows the circuit modeling of an eleven element LPA for simulation using circuit simulator, and Figure 9 is the layout of the eleven element passive LPA.

Calculation of design parameters for square patch microstrip antenna is shown in

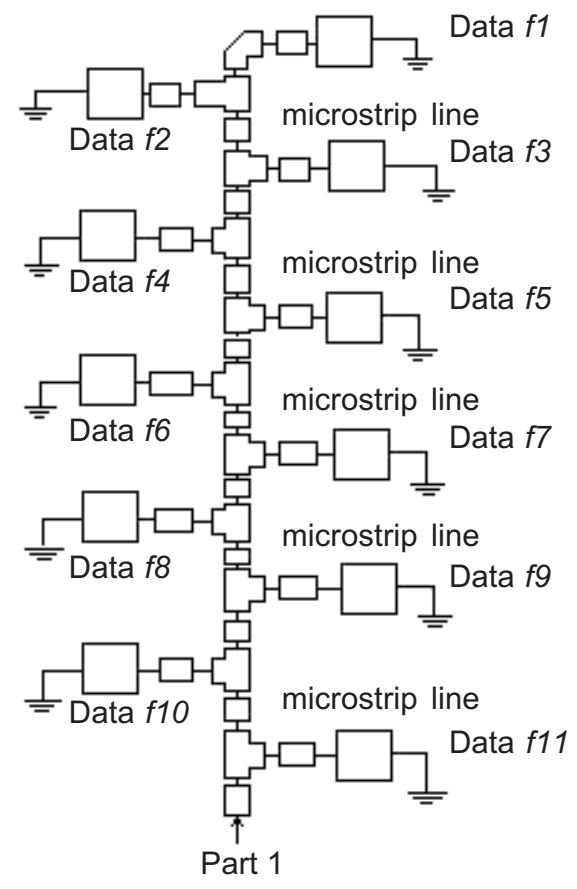

Figure 8 Circuit modeling of LPA

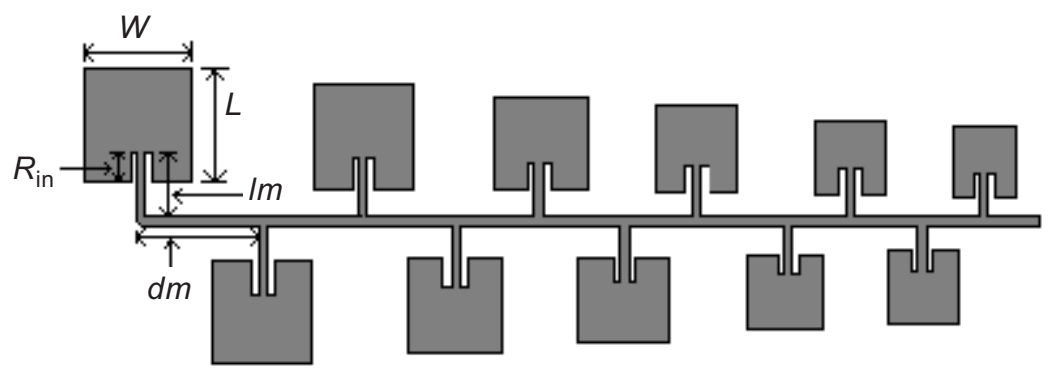

Figure 9 Eleven element LPA with inset feed 
Table 1 Design parameters for log periodic antenna with scaling factor of 1.05

\begin{tabular}{ccccc}
\hline Data & $\begin{array}{c}\text { Freq. } \\
(\mathbf{G H z})\end{array}$ & $\begin{array}{c}\mathbf{W}=\mathbf{L} \\
\mathbf{( m m )}\end{array}$ & $\begin{array}{c}\text { Quarter wave } \\
\text { length }(\mathbf{m m})\end{array}$ & $\begin{array}{c}\mathbf{R}_{\mathbf{i n}}(\mathbf{5 0 W}) \\
(\mathbf{m m})\end{array}$ \\
\hline $\mathrm{f}_{1}$ & 2.03 & 35.67 & 19.38 & 10.80 \\
$\mathrm{f}_{2}$ & 2.14 & 32.35 & 18.45 & 10.40 \\
$\mathrm{f}_{3}$ & 2.24 & 30.81 & 17.55 & 9.80 \\
$\mathrm{f}_{4}$ & 2.35 & 29.34 & 16.71 & 9.55 \\
$\mathrm{f}_{5}$ & 2.47 & 27.94 & 15.90 & 9.00 \\
$\mathrm{f}_{6}$ & 2.60 & 26.61 & 15.14 & 8.60 \\
$\mathrm{f}_{7}$ & 2.73 & 25.34 & 14.40 & 8.20 \\
$\mathrm{f}_{8}$ & 2.87 & 24.13 & 13.70 & 7.80 \\
$\mathrm{f}_{9}$ & 3.01 & 22.98 & 13.04 & 7.50 \\
$\mathrm{f}_{10}$ & 3.16 & 21.89 & 12.45 & 7.20 \\
$\mathrm{f}_{11}$ & 3.32 & 20.84 & 11.83 & 6.90 \\
\hline
\end{tabular}

Table 1. The substrate used is FR4 with dielectric constant of 4.7 and height of 1.6 $\mathrm{mm}$. The scaling factor $\tau=1.05$. The loss tangent of material is 0.019 .

\subsection{RESULT AND DISCUSSION}

The result of eleven element log periodic antenna is discussed in terms of bandwidth response, radiation pattern characteristic, cross polar isolation and gain relative to dipole and passive element.

\subsection{Bandwidth Response}

The measurement and simulation result of input return loss for the eleven element passive LPA is shown in Figure 10. The bandwidth from the measurement result is $63 \%$ and from the simulation result is $57 \%$. The resonances of the antenna can be seen by observing the dip in the return loss. There is a close agreement between the

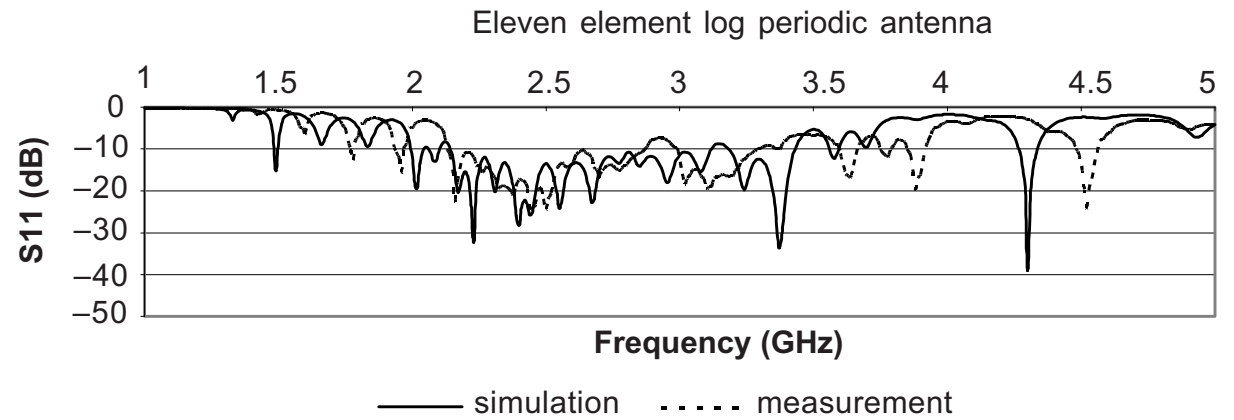

Figure $10 S_{11}$ passive log periodic antenna 
simulation and measurement result for the bandwidth. The simulation result gives a good approximation for the measurement even though the frequency has been shifted slightly from the simulation result. The shifting of the frequency is due to the substrate of FR4, which has dielectric constant varies between 4.0 and 4.7. In this design, the dielectric constant of 4.7 has been selected. Therefore, any variations of the dielectric constant will change the frequency of the antenna. The shifting of the frequency is also from the fabrication process of the hardware. Any changes in the dimension will affect the resonance frequency of the antenna.

\subsection{Cross-polar Isolation}

The co- and cross-polar responses are shown in Figure 11. The cross-polar isolation throughout the frequency band is between 10 and $30 \mathrm{~dB}$. The cross-polar isolation is at frequency 2.3 to $2.4 \mathrm{GHz}$ with the cross-polar isolation of $30 \mathrm{~dB}$.

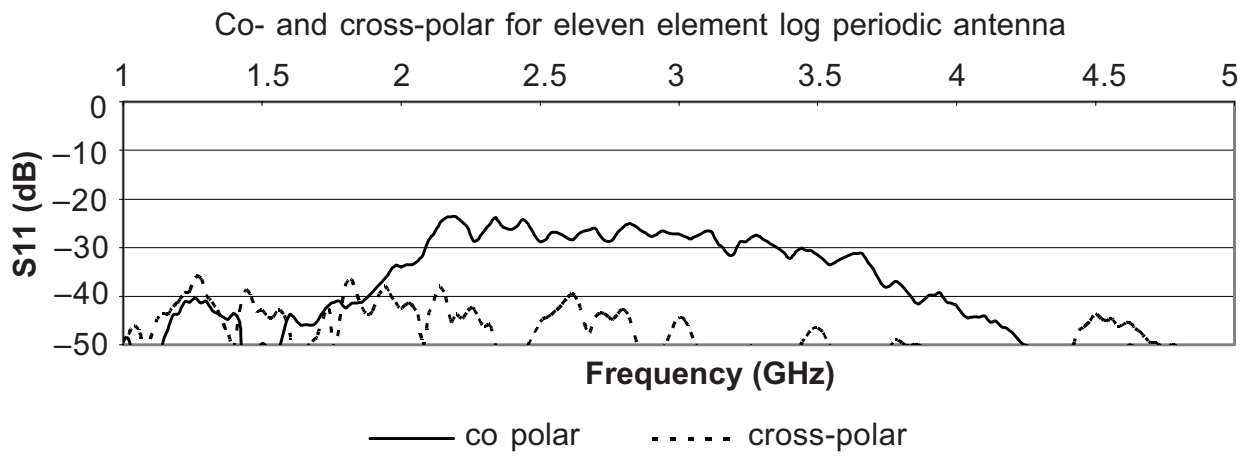

Figure $11 \mathrm{~S}_{21}$ response for passive LPA

\subsection{Gain Relative to Dipole Element}

The gain of this antenna is from -1 to $5 \mathrm{~dB}$, as shown in Figure 12. The highest gain is at frequency $2.3 \mathrm{GHz}$. The lowest gain is $-1 \mathrm{~dB}$ at $3.2 \mathrm{GHz}$. At any frequency, the number of array elements contributing to the radiation is dependent on the bandwidth of the individual radiators, and the scaling factor used in constructing the array. Therefore, adding more elements does not increase the peak gain. Instead, a reduction in peak gain is seen, possibly because the efficiency is degraded when more elements are added. 
Comparison between eleven element passive and dipole antenna

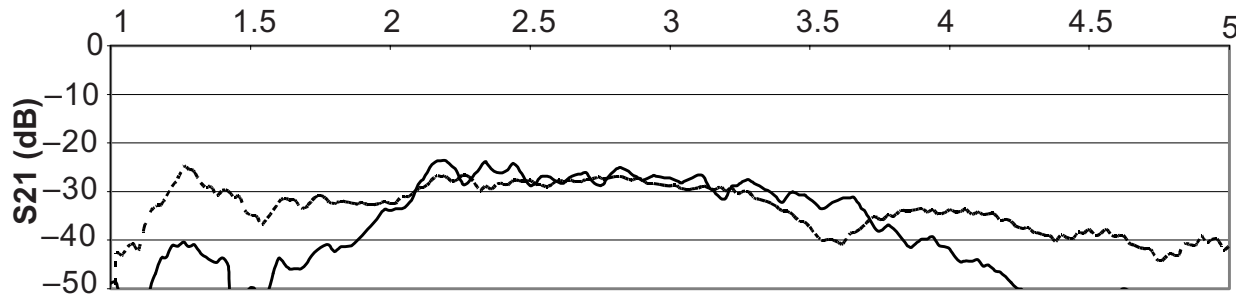

Frequency $(\mathrm{GHz})$

eleven element . . . . . dipole

Figure $12 S_{21}$ response relative to dipole antenna
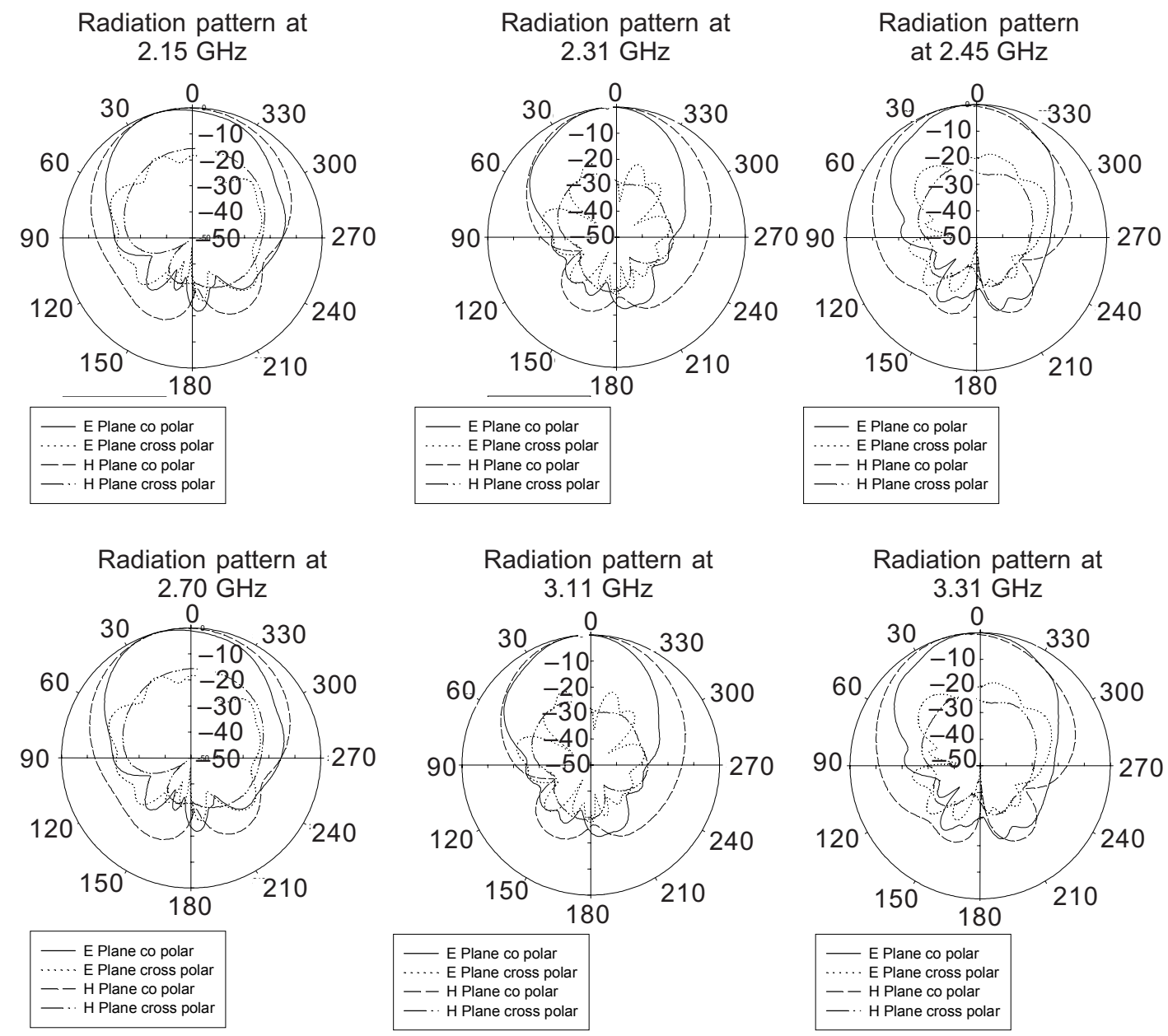

Figure 13 Radiation pattern for passive LPA 


\subsection{Radiation Pattern Characteristics}

Figure 13 shows the radiation pattern for the eleven element passive LPA at various frequencies. The radiation is in the broadside direction. The pattern has a narrow beam at higher frequency for $\mathrm{E}$ and $\mathrm{H}$ Plane. At lower frequency, $2.04 \mathrm{GHz}$, the crosspolar isolation for E Plane and $\mathrm{H}$ Plane is $10 \mathrm{~dB}$. The HPBW at this frequency is $90^{\circ}$ for $\mathrm{E}$ plane and $80^{\circ}$ for $\mathrm{H}$ plane. The measurement at the middle frequency, $2.77 \mathrm{GHz}$ shows that the cross-polar isolation for $\mathrm{E}$ Plane is $18 \mathrm{~dB}$ and $\mathrm{H}$ plane is $18 \mathrm{~dB}$. The $\mathrm{HPBW}$ at this frequency is $80^{\circ}$ for $\mathrm{E}$ Plane and $60^{\circ}$ for $\mathrm{H}$ Plane. For the higher frequency at $3.62 \mathrm{GHz}$, the cross-polar isolation for E Plane is $17 \mathrm{~dB}$ and $\mathrm{H}$ Plane is $18 \mathrm{~dB}$. The $\mathrm{HPBW}$ at this frequency is $40^{\circ}$ for $\mathrm{E}$ plane and $55^{\circ}$ for $\mathrm{H}$ Plane. Table 1 shows a summary of the measured results at different frequencies for the eleven element passive LPA. The average cross-polar isolation for the different frequencies is $20 \mathrm{~dB}$ for $\mathrm{E}$ and $\mathrm{H}$ Plane. The average $\mathrm{HPBW}$ is $40^{\circ}$ for $\mathrm{E}$ Plane and $60^{\circ}$ for $\mathrm{H}$ Plane.

\subsection{CONCLUSION}

Various techniques have been discussed to enhance the bandwidth of microstrip antenna. One of the technique is by using the log periodic antenna with inset feed. A bandwidth up to $1.8 \mathrm{GHz}$ is achieved by using an eleven element passive log periodic antenna LPA. The bandwidth has been increased from $2.8 \%$ for a single element antenna into $63 \%$ for the eleven element array. The cross-polar isolation of the log periodic antennas is in the range of 10 to $30 \mathrm{~dB}$. The typical HPBW of the log periodic antenna is $40^{\circ}$ for $\mathrm{E}$ Plane and $60^{\circ}$ for $\mathrm{H}$ Plane. The gain of the antenna relative to the dipole antenna ranges from -2 to $7 \mathrm{~dB}$. The radiation pattern is in the broadside direction of $\mathrm{E}$ and $\mathrm{H}$ plane. The $\mathrm{E}$ plane $\mathrm{HPBW}$ is smaller than the $\mathrm{H}$ Plane for LPA.

\section{REFERENCES}

[1] Garg, R., P. Bhartia, I. Bahl, and A. Itlipiboon. 2001. Microstrip Antenna Design Handbook. Norwood, USA: Artech House Inc.

[2] Long, S. A., and W. D. Walton. 1978. A Dual Frequency, Stacked Circular Disc Antenna. IEEE Antennas and Propagation Soc. International Symp. 260-263.

[3] Chen, C.H., A. Tulinfsetf, and R. M. Sorbello. 1984. Broadband Two Layer Microstrip Antenna. IEEE Antennas and Propagation Soc. International Symposium. 251-254.

[4] Katineni,R. V., U. Balaji, and A. Das. 1992. Improvement of Bandwidth in Microstrip Antennas Using Parasitic Patch. IEEE Antennas and Propagation Society International Symposium. 1943-1947.

[5] Wu, C. K., and K. L. Wong. 2000. Broadband Microstrip Antenna with Directly Coupled and Parasitic Patches. Microwave and Optical Tech. Lett. 22(5): 348-349.

[6] Mayes, P. E. 1992. Frequency Independent Antennas and Broad Band Derivatives Thereof. Proc. Of The IEEE. 80(1): 103-112.

[7] Hall, P. S. 1986. Multioctave Bandwidth Log Periodic Microstrip Antenna Array. IEE Proceeding Pt H. 133(2): 127-136.

[8] Pues, H., J. Bogsers, R. Pieck, and A. Van De Capelle. 1981. Wideband Quasi Log Periodic Microstrip Antenna. IEE proceeding part H. 128(3): 159-163. 
[9] Ooi, B.L., K. Chew, and M.S. Leong. 2000. Log Periodic Slot Antenna Array. Microwave and Optical Technology Letters. 25(1): 24-27.

[10] Compton,R. C., R. C. McPhedran, Z. Popovic, G. M. Rebeiz. P. P. Tong, and D. B. Rutledge. Bow Tie Antennas on a Dielectric Half Space: Theory and Experiment. IEEE Trans. On Antennas and Propagation. 35(6): 622-631.

[11] Poddar, D. R., J. S. Chatterjee, and S. K. Chowdhury. 1983. On Some Broadband Microstrip Resonators. IEEE Trans. Antenna and Propagation. 31(1): 193-194.

[12] Ooi, B. L., and Q. Shen. 2000. A Novel E Shaped Broadband Microstrip Patch Antenna. Microwave and Optical Tech. Letters. 27(5): 348-352.

[13] Hall, P. S. 1987. Probe Compensation in Thick Microstrip Patches. Electronics Letter. 21(1): 606-607.

[14] Pozar, D. M. Microstrip Antenna Aperture Coupled to Microstrip Line. Electronics Letters. 21(2): 49-50.

[15] Pozar, D. M., and B. Kaufman. 1987. Increasing the Bandwidth of a Microstrip Antenna by Proximity Coupling. Electronic. Letters. 23(8): 368-369.

[16] Pues, H. F., and A. R. Van de Capelle. 1989. An Impedance-matching Technique for Increasing the Bandwidth of Microstrip Antennas. IEEE Trans. Antennas Propagation. 37: 1345-1354.

[17] Guo,Y. X., K. M. Luk, and K. F. Lee. 2000. A Dual Band Patch Antena with Two U Shaped Slots: Microwave and Optical Tech. Letters. 26(2): 73-75.

[18] Chen H. M., J. Y. Sze, and Y. F. Lin. 2000. A Broadband Rectangular Microstrip Antenna with a Pair of U Shaped Slots. Microwave and Optical Tech. Letters. 27(5): 369-370.

[19] Sze, S. Y., and K. L. Wong. 1998. Broadband Rectangular Microstrip Antenna with Pair of Toothbrushshaped Slots. Electronics Letter. 34(23): 2186-2187. 